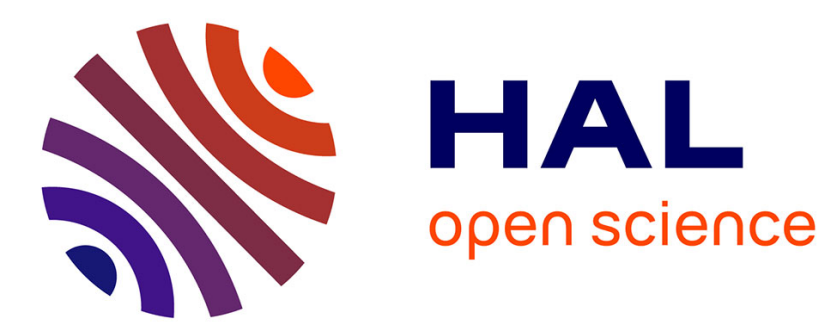

\title{
MoSe2 thin films synthesized by solid state reactions between Mo and Se thin films
}

\author{
J. Pouzet, J.C. Bernede
}

\section{To cite this version:}

J. Pouzet, J.C. Bernede. MoSe2 thin films synthesized by solid state reactions between Mo and Se thin films. Revue de Physique Appliquée, 1990, 25 (8), pp.807-815. 10.1051/rphysap:01990002508080700 . jpa-00246242

\section{HAL Id: jpa-00246242 https://hal.science/jpa-00246242}

Submitted on 1 Jan 1990

HAL is a multi-disciplinary open access archive for the deposit and dissemination of scientific research documents, whether they are published or not. The documents may come from teaching and research institutions in France or abroad, or from public or private research centers.
L'archive ouverte pluridisciplinaire HAL, est destinée au dépôt et à la diffusion de documents scientifiques de niveau recherche, publiés ou non, émanant des établissements d'enseignement et de recherche français ou étrangers, des laboratoires publics ou privés. 


\title{
$\mathrm{MoSe}_{2}$ thin films synthesized by solid state reactions between Mo and Se thin films
}

\author{
J. Pouzet $\left({ }^{1}\right)$ and J. C. Bernede $\left({ }^{2}\right)$ \\ (') Laboratoire de Physique Cristalline, IPCM, UMR110, F-44072 Nantes Cedex, France \\ ( ${ }^{2}$ ) Laboratoire de Physique des Matériaux et Composants de l'Electronique, Faculté des Sciences et des \\ Techniques de Nantes, 2 rue de la Houssinière, 44072 Nantes Cedex 3, France
}

(Reçu le 3 juillet 1989, révisé le 14 mars 1990, accepté le 4 mai 1990)

\begin{abstract}
Résumé. - Après dépôt par évaporation de fines couches superposées de molybdène et de sélénium $\left(\mathrm{Mo} / \mathrm{Se} / \mathrm{Mo} / \mathrm{Se} . . . \mathrm{Mo}\right.$ ), un recuit de ces structures permet l'obtention de couches minces de $\mathrm{MoSe}_{2}$. Les couches ont été caractérisées par diffraction des rayons $\mathrm{X}$, spectroscopie de photoélectrons (XPS), microscopie électronique à balayage, microsonde électronique, absorption optique et par étude de l'évolution de leur résistivité en fonction de la température. On montre que, quoique les couches soient stœchiométriques, la structure hexagonale de $\mathrm{MoSe}_{2}$ est difficile à obtenir, même après recuits à des températures de $850 \mathrm{~K}$. Cependant, des couches recuites sous pression de sélénium à seulement $770 \mathrm{~K}$ sont bien cristallisées. La conductivité électrique est contrôlée par une conduction par sauts dans le domaine des basses températures (80-200 K) et par diffusion des porteurs au niveau des joints de grains entre 300 et $550 \mathrm{~K}$.
\end{abstract}

\begin{abstract}
MoSe}_{2}$ coatings were obtained by solid state reaction, induced by annealing, between the Mo and Se constituents in thin films form. The films have been investigated by X ray analysis, XPS analysis, scanning electron microscopy, electron microprobe analysis, optical absorption and electrical resistivity measurements. It was found that, while the films are stoichiometrics, $\mathrm{MoSe}_{2}$ in the hexagonal form was difficult to obtain even at temperature as high as $850 \mathrm{~K}$. However thin films annealed under selenium pressure at only $770 \mathrm{~K}$ are well crystallized. The electrical resistivity is governed by hopping conduction in the low temperature range (80$200 \mathrm{~K})$ and by grain boundary scattering mechanisms at higher temperature.
\end{abstract}

\section{Introduction.}

$\mathrm{MoSe}_{2}$ is a semiconductor with a band gap of about $1.1 \mathrm{eV}$ [1] which can be an efficient electrode in the realization of photoelectrochemical solar cells [2-5].

In earlier papers $[6,7]$ we have described a process for obtaining stoichiometric $\mathrm{MoSe}_{2}$ thin films. The layers prepared by d.c. diode sputtering were annealed under selenium pressure at $770 \mathrm{~K}$ for $24 \mathrm{~h}$ and finally heated under dynamic vacuum at $670 \mathrm{~K}$ for $10 \mathrm{~h}$. We have shown that stoichiometric thin films with appropriate structure and band gap are obtained.

Nowaday, $\mathrm{MoSe}_{2}$ thin films have been realized only by sputtering [6-10]. But for photovoltaic thin film structures, the grain size, the orientation and the electrical properties of these $\mathrm{MoSe}_{2}$ thin films need improvement.

In this paper, another process to obtain stoichiometric thin films is described. As proposed by Dang Tran Quan [11] in the case of SnSe, we have prepared $\mathrm{MoSe}_{2}$ thin films by solid state reaction between the constituents in thin films form.

\section{Film preparation and characterization.}

2.1 SYNTHESIS OF THE FILMS. - The substrates were polished glass, silica, mica sheet, chemically cleaned and outgassed in situ prior to deposition by heating at $400 \mathrm{~K}$ during $1 \mathrm{~h}$. The substrate temperature was controlled by a copper/constantan thermocouple attached with silver paste to the surface of the sample. The substrate temperature could be monitored between 150 and $850 \mathrm{~K}$. The films were deposited in vacuum (base pressure $5 \times 10^{-5} \mathrm{~Pa}$ ) by evaporation of Mo and Se. Mo was deposited by electron beam evaporation and Se by classical thermal evaporation from a tantalum crucible. The purity of the Mo and Se used to grow the films was : 99,999. The $\mathrm{MoSe}_{2}$ films were synthesized by solid 
state reaction from thin films [11]. Layers of Mo and Se were sequentially deposited. The evaporation rate $(0.1 \mathrm{~nm} / \mathrm{s}$ for Mo and $1 \mathrm{~nm} / \mathrm{s}$ for Se) and the film thickness were measured in situ by the vibrating quartz method. The layers thicknesses were calculated to achieve the desired composition and varied from $25 \mathrm{~nm}$ to $35 \mathrm{~nm}$. The number of layers $(\mathrm{Mo} / \mathrm{Se} / \mathrm{Mo} / \mathrm{Se} / \mathrm{Mo} . .$.$) varied from 7$ to 13 . The whole thickness of the films was controlled by a stylus. After deposition the multilayer structures were annealed under dynamic vacuum. Selenium has a high vapour pressure while molybdenum has not. Therefore, to prevent selenium evaporation during annealing, a molybdenum layer was deposited the last. The composition of the samples was checked by electron microprobe analysis and by XPS analysis.

2.2 THIN FILM CHARACTERIZATION. - The scanning electron micrographs were obtained with a JEOL scanning electron microscope. The roughness of the surface of the films was visualized by scanning electron micrograph and checked by the stylus. The structure of the films was examined using an X-ray goniometer. The preferential orientation of crystallites, $F$, and the degree of crystallite order, $G$, were deduced from the X-ray diffraction patterns. The grain size was estimated from the full width at half maximum (FWHM) of the diffraction peak $[6,7]$.

XPS data were obtained with $\mathrm{MgK} \alpha$ radiation (1 $253.6 \mathrm{eV}$ ) and $50 \mathrm{eV}$ pass energy setting, giving an overall energy resolution of $1 \mathrm{eV}$. The quantitative studies were based in the determination of the Se3d and Mo3d peak area with respectively 0.57 and 2.5 as sensitivity factors (the sensitivity factors of the spectrometer are given by Leybold the manufacturer. XPS analysis has been carried out at Nantes University of Nantes - CNRS). In the case of insulating substrates $(10 \times 11 \times 1 \mathrm{~mm})$, the samples were grounded with silver paste. The oxygen pollution in depth was studied by recording successive XPS spectra obtained after argon ion etching for short periodes. Sputtering was accomplished at pressures of less than $5 \times 10^{-4} \mathrm{~Pa}$, a $10 \mathrm{~mA}$ emission current and a $5 \mathrm{kV}$ beam energy using an ion gun. The $\mathrm{Ar}^{+}$ion beam could be rastered over the entire sample surface. Quantitative analysis have also been obtained by electron microprobe analysis.

The optical measurements were carried out at room temperature using a carry spectrophotometer. The optical density was measured at wavelengths from $2 \mu \mathrm{m}$ to $0.4 \mu \mathrm{m}$. The absorption coefficient $\alpha$ has been calculated from the measured transmission $T$ of two samples of different thicknesses [6].

Any errors incurred in the values of incertainties induced by this technique are much less than the errors in the thickness measurements, which dominate the experimental errors.

The energy gap is determined by extrapolating different plots of $\alpha=A\left(h \nu-E_{0}\right)^{n}$ to zero absorption, $A$ being a constant, $h$ the Planck constant and $\nu$ the frequency, $n$ can be anywhere in the range 1-2, $\mathrm{MoSe}_{2}$ being a layered indirect gap semiconductor [1].

For electrical measurements, metal electrodes were evaporated after $\mathrm{MoSe}_{2}$ synthesis. The gold was selected because gold thin films gave a good ohmic contact [12]. The film d.c. conductance was measured with an electrometer (Keithley 617) between 80 and $550 \mathrm{~K}$.

\section{Experimental results.}

While an annealing of amorphous $\mathrm{MoSe}_{2}$ sputtered thin films under selenium pressure for $24 \mathrm{~h}$ at $770 \mathrm{~K}$ gives stoichiometric crystallized thin films $[6,7]$, in situ annealing under dynamic vacuum of the multilayer structures at temperature as high as $850 \mathrm{~K}$ gives only stoichiometric but badly crystallized films. Therefore, in order to obtain well crystallized films, some samples have been post annealed under selenium pressure as described in an earlier paper [6]. The samples were placed with a small amount of selenium in a vacuum sealed glass tube and heated at $770 \mathrm{~K}$ for $24 \mathrm{~h}$. Finally, in order to sublimate the excess of selenium condensed at the surface of the layers during the cooling of the glass tube, the samples were annealed under dynamic vacuum for $24 \mathrm{~h}$ at $670 \mathrm{~K}$ [7].

Samples only annealed in situ are referred as belonging to group $\mathrm{A}$ and the others to group $\mathrm{B}$.

Over the film thickness range investigated $(0.2$ to $0.5 \mu \mathrm{m}$ ), very few differences in the experimental results were observed from sample to sample.

3.1 X-RAY PHOTOELECTRON SPECTROSCOPY AND ELECTRON MICROPROBE ANALYSIS. - After annealing, XPS are identical for all the specimens (A or B), O1s, Mo3d and Se3d lines are shown figure 1 and figure 2 for multilayer structures before and after annealing respectively. The position of the lines for the oxides and the elements are shown as references [13]. Also reference spectra were obtained by us from $\mathrm{MoSe}_{2}$ powder stuck on a copper substrate. The $\mathrm{MoSe}_{2}$ powder analyzed was supplied by "Alfa Division». The purity of the powder used was $99 \%$. The chemical shifts of the lines and the energy difference between the Se3d and the $\mathrm{Mo}_{5 / 2}$ peak spectra were compared with those of the $\mathrm{MoSe}_{2}$ powder (Tab. I).

The spectra of Se3d and Mo3d regions of the samples not annealed are shown in figures la and 1b. It is evident from these figures that there is not any selenium at the surface of the film before any sputtering. The binding energy of the Mo3d doublet correspond to the $\mathrm{MoO}_{3}$ compound. After ion sputtering the Se3d peak appears, corresponding to the first underlayer of selenium while there is a shift 


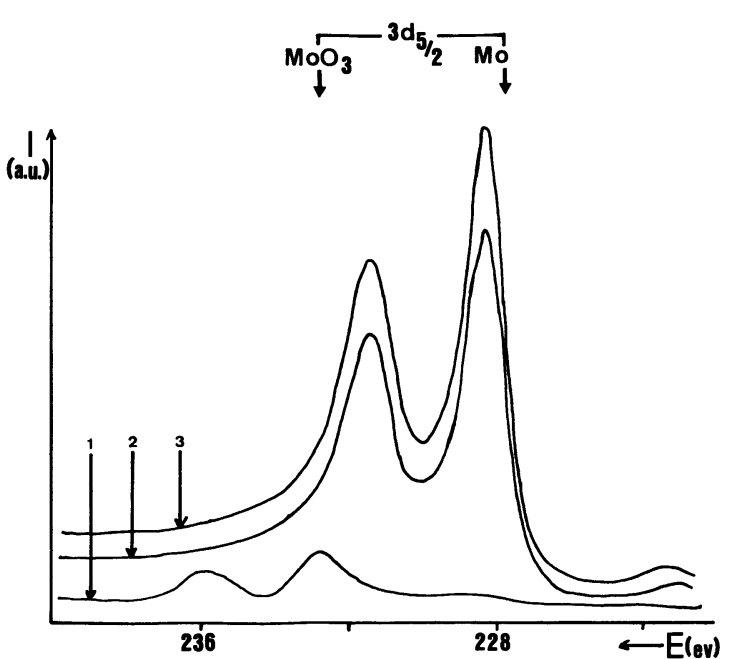

a)

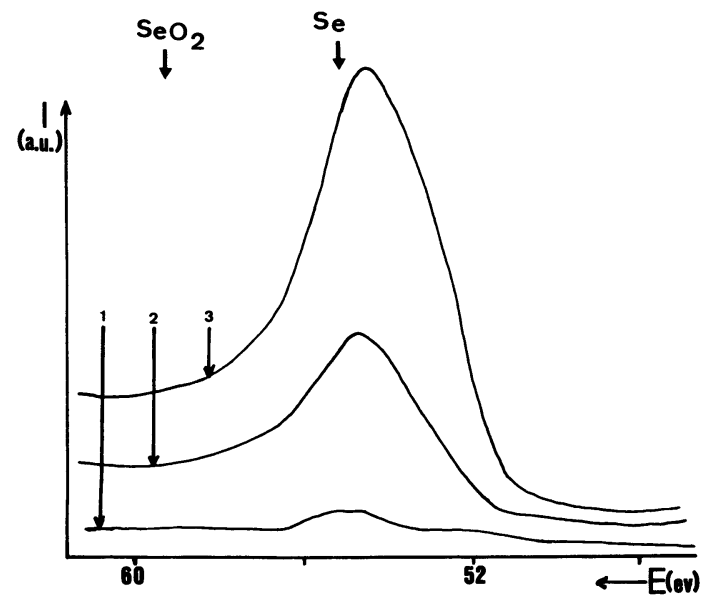

b)

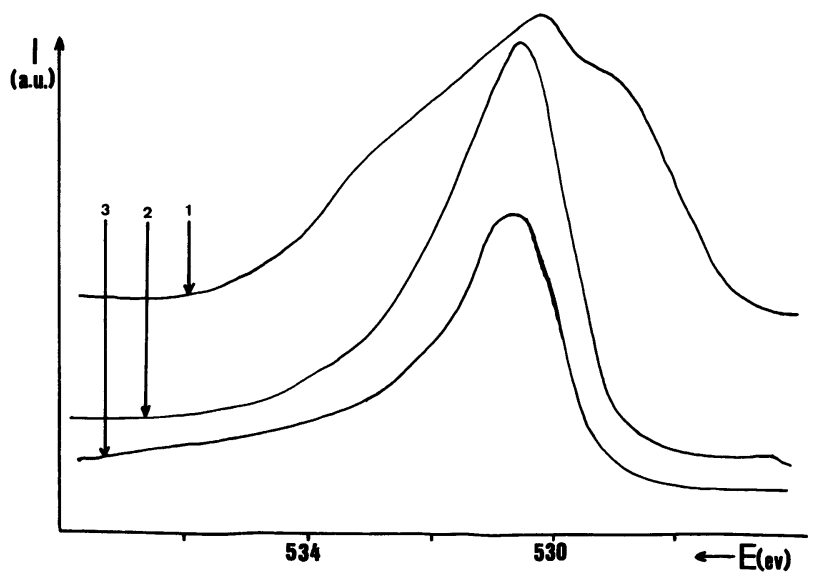

c)

Fig. 1. - XPS spectra of (a) Mo3d, (b) Se3d, (c) 01 s. 1) $\mathrm{MoSe}_{2}$ multilayer before annealing. 2) $\mathrm{MoSe}_{2}$ multilayer before annealing and after an etching of $1 \mathrm{~min}$. 3) $\mathrm{MoSe}_{2}$ multilayer before annealing and after an etching of $3 \mathrm{~min}$.

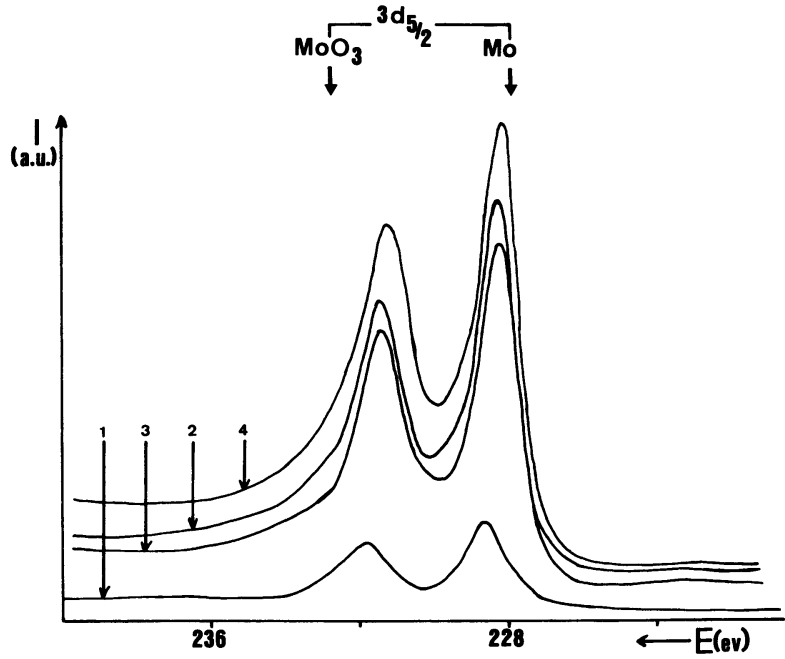

a)

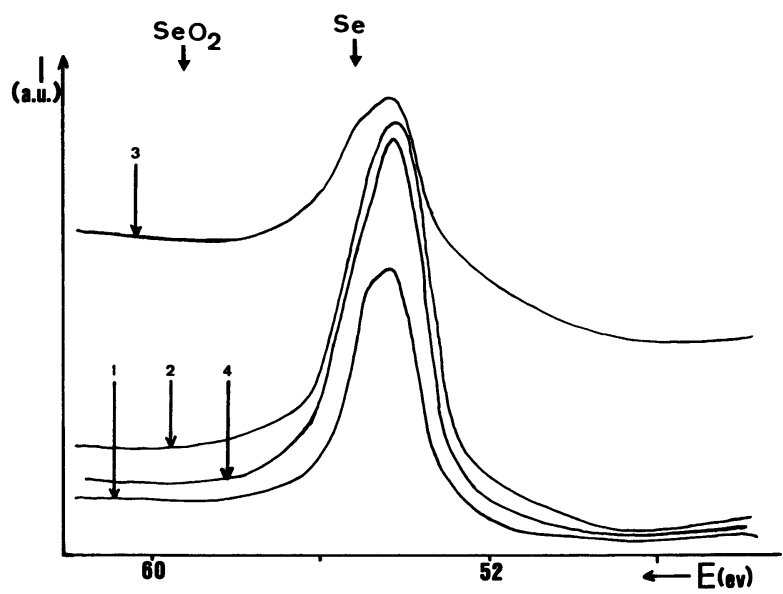

b)

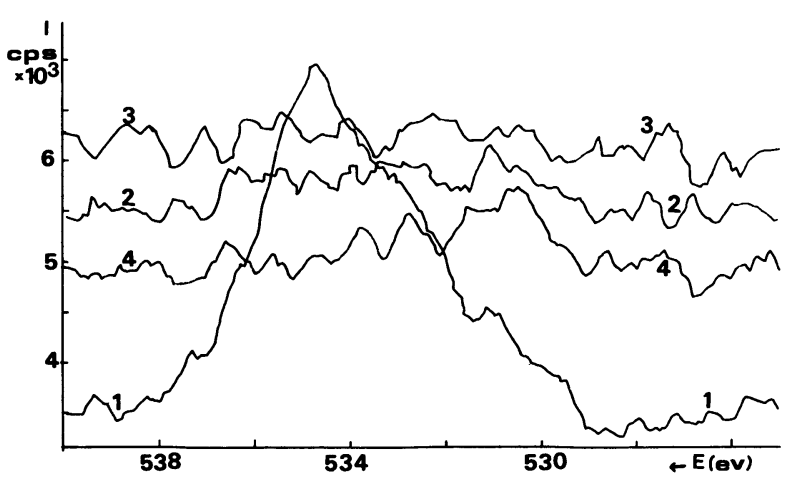

c)

Fig. 2. - XPS spectra of (a) Mo3d, (b) Se3d, (c) $01 \mathrm{~s}$. 1) $\mathrm{MoSe}_{2}$ multilayer after annealing (group A). 2) $\mathrm{MoSe}_{2}$ multilayer after annealing and after an etching of $1 \mathrm{~min}$. 3) $\mathrm{MoSe}_{2}$ multilayer after annealing and after an etching of 3 min. 4) $\mathrm{MoSe}_{2}$ multilayer after annealing (group B) and after an etching of $2 \mathrm{~min}$. 
Table I. - $\mathrm{MoSe}_{2}$ XPS analysis.

\begin{tabular}{|c|c|c|c|c|c|c|}
\hline \multirow{2}{*}{ Sample } & \multicolumn{3}{|c|}{$\begin{array}{l}\text { Binding energy }(\mathrm{eV}) \\
\text { after etching }\end{array}$} & \multirow{2}{*}{$\begin{array}{c}\text { Energy dif- } \\
\text { ference } \Delta E \\
(\mathrm{eV}) \text { between } \\
\text { Mo3d } \mathrm{d}_{5 / 2} \\
\text { and } \mathrm{Se} 3 \mathrm{~d}\end{array}$} & \multicolumn{2}{|c|}{ Composition } \\
\hline & $\mathrm{Mo}_{3 / 2}$ & $\operatorname{Mo3d}_{5 / 2}$ & $\operatorname{Se} 3 d$ & & $\%$ at Mo & $\%$ at $\mathrm{Se}$ \\
\hline $\mathrm{MoSe}_{2}$ powder & 231.7 & 228.5 & 54.25 & 174.25 & 32 & 68 \\
\hline $\begin{array}{l}\text { Thin films : } \\
\text { Before annealing } \\
\text { group A } \\
\text { group B }\end{array}$ & $\begin{array}{l}231.5 \\
231.7 \\
231.2\end{array}$ & $\begin{array}{l}228.5 \\
228.5 \\
228.5\end{array}$ & $\begin{array}{l}54.8 \\
54.1 \\
54.4\end{array}$ & $\begin{array}{l}173.7 \\
174.4 \\
174.1\end{array}$ & $\begin{array}{l}31.5 \\
36^{*} \\
32 \\
34.2^{*}\end{array}$ & $\begin{array}{l}68.5 \\
64^{*} \\
68 \\
65.8^{*}\end{array}$ \\
\hline
\end{tabular}

* Microprobe analysis.

in the binding energy of the Mo3d doublet of about $4.7 \mathrm{eV}$ (Fig. 1a2). Therefore, as shown by the arrows in figure 1 , we assign this doublet to the metal Mo.

There is a little chemical shift $(0.5 \mathrm{eV})$ of the Mo doublet between the spectra obtained after an etching of $1 \mathrm{~min}$ and one of $3 \mathrm{~min}$ (Fig. 1a). As before any ion sputtering, the molybdenum is oxydized. This little chemical shift show us that even after an etching of $1 \mathrm{~min}$ there is still some bounds between oxygen and molybdenum, i.e. the first atom layers of molybdenum are polluted by oxygen.

In the case of in situ annealed sample $(24 \mathrm{~h}$ at $850 \mathrm{~K}$ ), it is evident from figure 2 that even at the surface the molybdenum is not oxydized, i.e. the Mo is bounded to Se which prevent oxydation.

However, as shown in figure 2, after ion sputtering, there is a little chemical shift $(0.3 \mathrm{eV})$ of the Mo doublet which, probably, correspond to a few bounds between oxygen and molybdenum at the surface of the films. This fact is corroborated by the O1s line which disappears after 2 min of ion sputtering.

Table I shows that the energy difference between the Se3d and Mo3d $\mathrm{d}_{5 / 2}$ peak spectra is $174.4 \mathrm{eV}$ for annealed films which is the value obtained with $\mathrm{MoSe}_{2}$ powder, while before annealing the energy difference is $173.7 \mathrm{eV}$. This correlation between the thin film structure and the energy difference between the Se3d and Mo3d $d_{5 / 2}$ peak spectra allows us to check whether Mo and Se are bounded in the $\mathrm{MoSe}_{2}$ phase or not.

XPS surface analysis (Tab. I) shows that stoichiometric films are obtained after annealing. In figures $2 \mathrm{c} 3$ and $2 \mathrm{c} 4$ we can see that after an etching of two minutes the O1s peak has nearly disappeared for the group A samples (the signal to noise ratio is too small to obtain a reliable quantification), while he has not for the group B (about 8 at\%). Therefore the pollution is smaller for in situ annealed films.
After ion etching, even in the case of the $\mathrm{MoSe}_{2}$ powder reference, there is a molybdenum excess bound to the higher etching speed of selenium.

Therefore, to discuss the depth profiling of the layers we have used the $\mathrm{MoSe}_{2}$ powder as reference (Fig. 3).

As we can see in figure 3, the depth profilings of the layers were identicals to that of the $\mathrm{MoSe}_{2}$ powder reference. We can conclude that the films are stoichiometrics, not only at the surface but even in depth.

This result was checked by microprobe analysis. The electron microprobe analysis, which is a bulk analysis technic confirms the stoichiometry of the films (Tab. I $\pm 1.5 \%$ atomic).

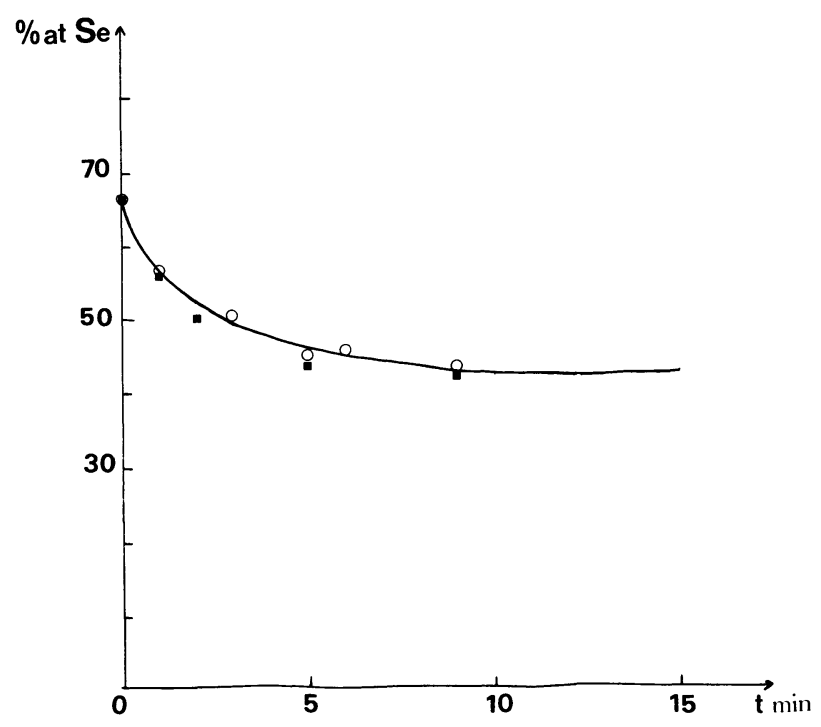

Fig. 3. - XPS elemental profil through $\mathrm{MoSe}_{2}$ samples : (—) $\mathrm{MoSe}_{2}$ powder reference; (ם) group A ; (O) group B. 


\subsection{STRUCTURAL CHARACTERIZATION : X-RAY DIF-} FRACTION AND SCANNING ELECTRON MICROSCOPY.

- The films before annealing are shiny (smooth). After annealing, A samples were a little less brilliant, but only B samples have tarnished which is typical of polycrystalline thin films with rough surface.

This evolution is corroborated by talystep profil. As shown is figure 4, the surface of the samples of the group $A$ is less disturbed than the surface of the samples of the group B.

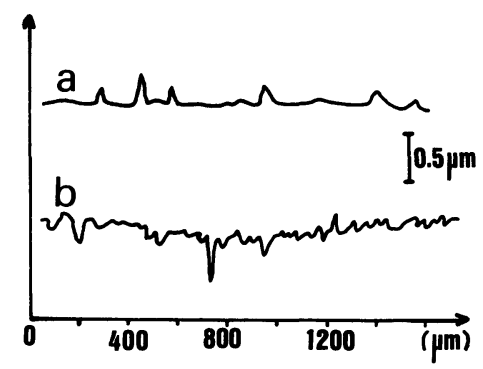

Fig. 4. - Surface roughness of the samples A (a) and B (b) visualised by the stylus.

Photographs showing the surface morphology after annealing of the samples for the group A and B are shown in figures $5 \mathrm{a}$ and $5 \mathrm{~b}$ respectively. The surfaces in all two cases appear relatively smooth and granular. No evidence of cracking could be observed in samples. However, the surface of the group B appears to be a little more textured than the surface of the samples of the group A.

The results deduced from the $\mathrm{X}$-ray spectra (Fig. 6) are retailled in table II and they are compared to preceding results obtained with post-annealed sputtered thin films $[6,7]$. These results show the mean crystallite shape to be like a column with

Table II. - Preferentiel orientation, crystallize size of $\mathrm{MoSe}_{2}$ thin films (group B - glass substrate annealing time $24 \mathrm{H}$ ).

\begin{tabular}{|c|c|c|c|c|c|}
\hline \multirow{2}{*}{ Sample } & \multirow{2}{*}{$F_{00 \ell}(\%)$} & \multirow{2}{*}{$F_{h k 0}(\%)$} & \multicolumn{2}{|c|}{ Grain size (nm) } & \multirow{2}{*}{$G$} \\
\cline { 4 - 5 } & & & $D_{002(/ / c)}$ & $D_{100(\perp c)}$ & \\
\hline $\mathrm{n}^{\circ} 10$ & 70 & 10 & 100 & 16 & 9.5 \\
$\mathrm{n}^{\circ} 13$ & 80 & 5 & 220 & 25 & 8.2 \\
$\mathrm{n}^{\circ} 15$ & 85 & 5 & 500 & - & 5.6 \\
\hline sputtered & & & & & \multirow{2}{*}{ DC films } \\
\hline
\end{tabular}

$-F_{00 \ell}:$ degree of preferred $(00 \ell)$ type orientation, i.e. crystallites with the $c$ axis perpendicular to the plane of the substrate.

$-F_{h k 0}:$ degree of preferred $(k h 0)$ type orientation, i.e. crystallites with the $c$ axis parallel to the plane of the substrate.

$-G \quad$ : ratio of crystallite phase content to the phase providing the non-coherent scattering of X-ray radiation [23].

REVUE DE PHYSIQUE APPLIQUÉE. - T. 25, N 8, AOÛT 1990

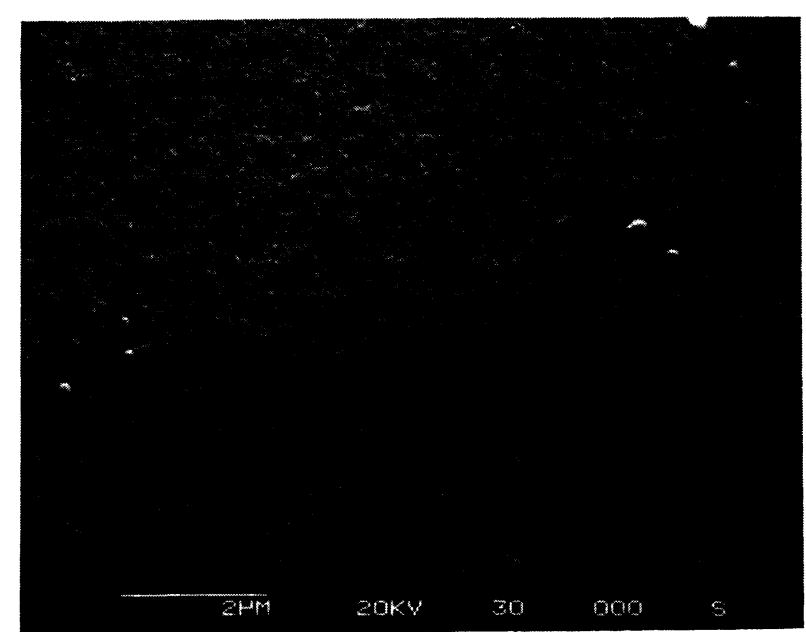

a)

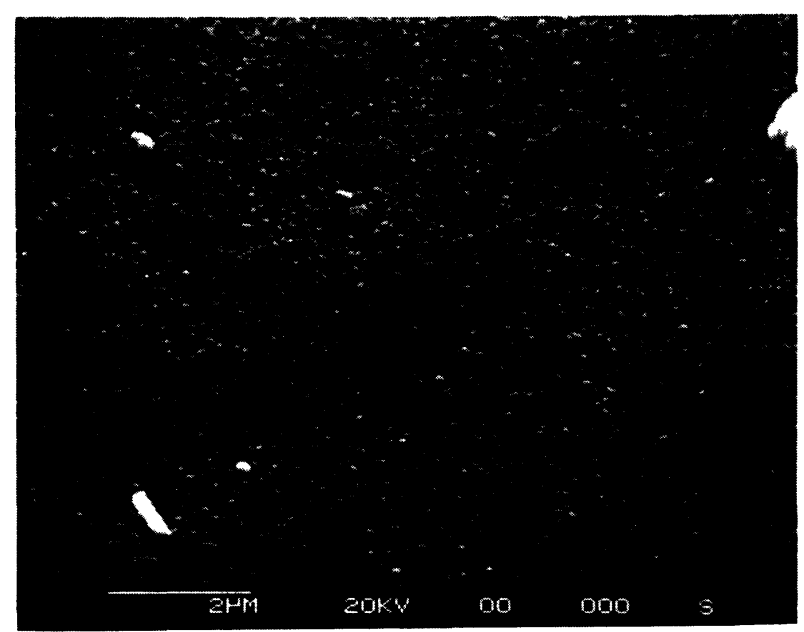

b)

Fig. 5. - Scanning electron micrographs showing the variation in morphology for the samples of the group A (a) and for the samples of the group B (b).

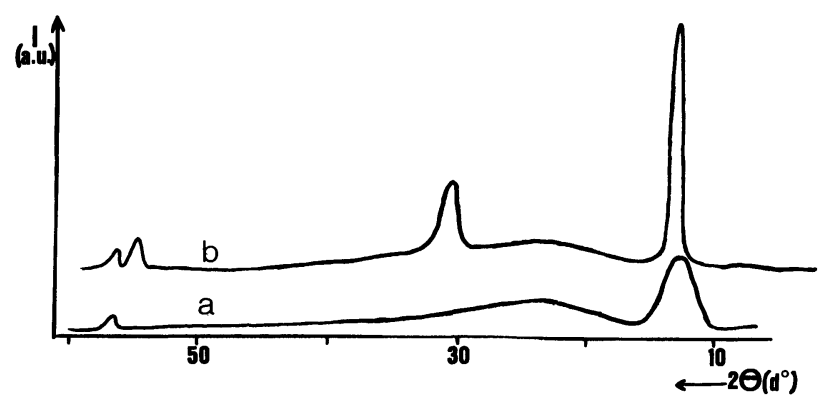

Fig. 6. - X-ray diffraction patterns of $\mathrm{MoSe}_{2}$ thin films : a) group $\mathbf{A}$; b) group $\mathbf{B}$.

the large dimension in the $c$ direction and the smaller dimension in the basal, $a b$, plane. About $80 \%$ of the crystallites have their $c$ axis perpendicular to the plane of the substrate. For the badly crystallized specimens of the group A two peaks only are visible. Therefore we cannot obtain significative value of $F$. 
The FWHM method gives a value of about 10 to $20 \mathrm{~nm}$ as the grain size along the $c$ axis, which is smaller than the grain size of the group B specimens.

3.3 OPTICAL ABSORPTION PROPERTIES. - The variation in the optical absorption with the photon energy $h \nu$ is shown in figure 7 for group $\mathrm{A}$ and group B samples.

The optical band gap of the $\mathrm{MoSe}_{2}$ layers of the group A was determined to be about 1.1 and $1.54 \mathrm{eV}$ by extrapolating the straight lines of $\alpha^{1 / 2} v s$. $E$ and $\alpha$ vs. $E$ respectively, while it is about 0.9 and $1.14 \mathrm{eV}$ with layers of the group $\mathrm{B}$.

We can see figure 7 that the absorption below the threshold energy value is still important which may induce large incertainty on the gap determination. Therefore we can only conclude that the values obtained for the band gap of the $\mathrm{MoSe}_{2}$ films is of the same order than that of $\mathrm{MoSe}_{2}$ single crystals.

The high absorption coefficient below the threshold energy value is bound to the roughness of the surface of the films as shown by figure 4 and figure 7.

The scattering of the incident light increases as the roughness of the sample increases. Therefore we can think that the absorption below the threshold energy value is bound to the morphological inhomogeneity of the film and correspond to high scattering (wrong absorption) of the light by disoriented microcrystals.

3.4 RESISTIVITY STUDIES. - It can be seen table III that the ambiant temperature conductivity of the films decreases by two or three decades compared to $\mathrm{MoSe}_{2}$ DC sputtered films [6] which is an improvement very significant in order to utilize $\mathrm{MoSe}_{2}$ as an efficient electrode in the realization of photoelectrochemical solar cells.

The temperature dependence of the electrical resistivity between 80 to $550 \mathrm{~K}$ is shown in figure 8 for typical samples.

In this temperature range, the resistivity does not follow an Arrhenius dependence, the sample exhibiting marked variations in $\partial \operatorname{Ln} \rho / \partial T$ with temperature. The observed slopes are always increasing with the temperature.

Table III. - Physical parameters deduced from electrical measurements.

\begin{tabular}{|c|c|c|}
\hline Sample & $\begin{array}{c}\text { Room temperature } \\
\sigma_{300 \mathrm{~K}}\left(\Omega^{-1} \mathrm{~cm}^{-1}\right)\end{array}$ & $\begin{array}{c}\text { Barrier height } \\
q \phi_{\mathrm{B}}(\mathrm{eV})\end{array}$ \\
\hline $\begin{array}{l}\text { Group A } \\
\text { Group B }\end{array}$ & $\begin{array}{l}0.27 \\
0.15\end{array}$ & 0.17 \\
& 0.14 \\
\hline $\begin{array}{l}\text { Sputtered } \\
\text { DC films }\end{array}$ & $\begin{array}{c}0.1 \times 10^{-2} \\
\text { to } 0.01 \times 10^{-2}\end{array}$ & 0.25 \\
\hline
\end{tabular}

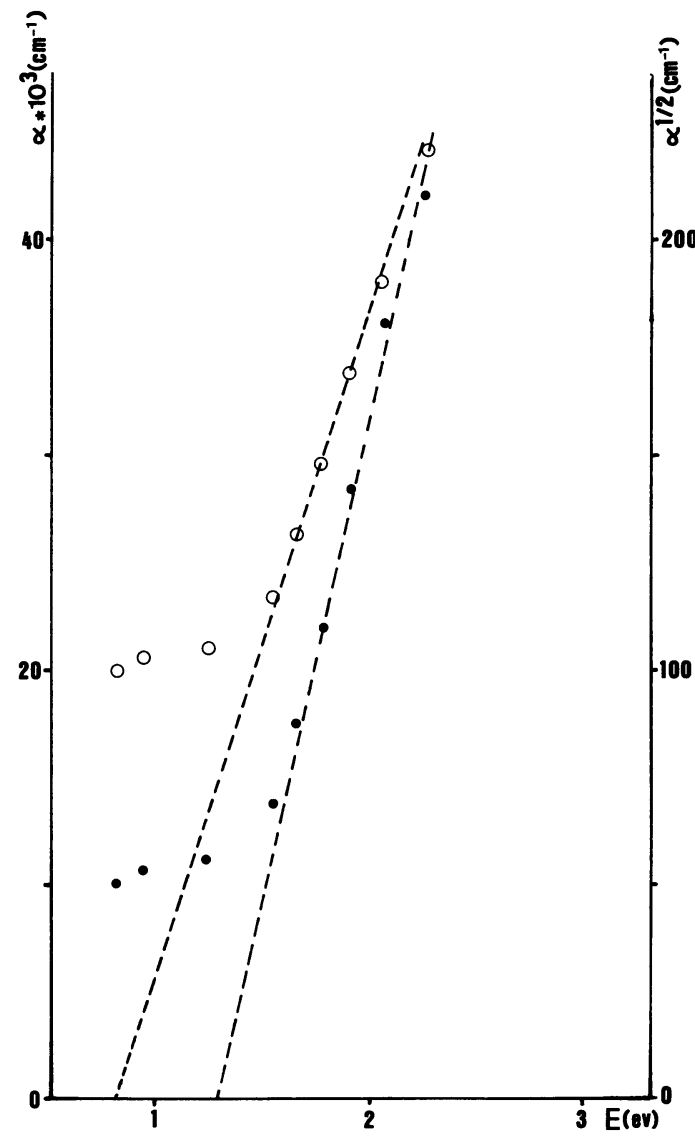

a)

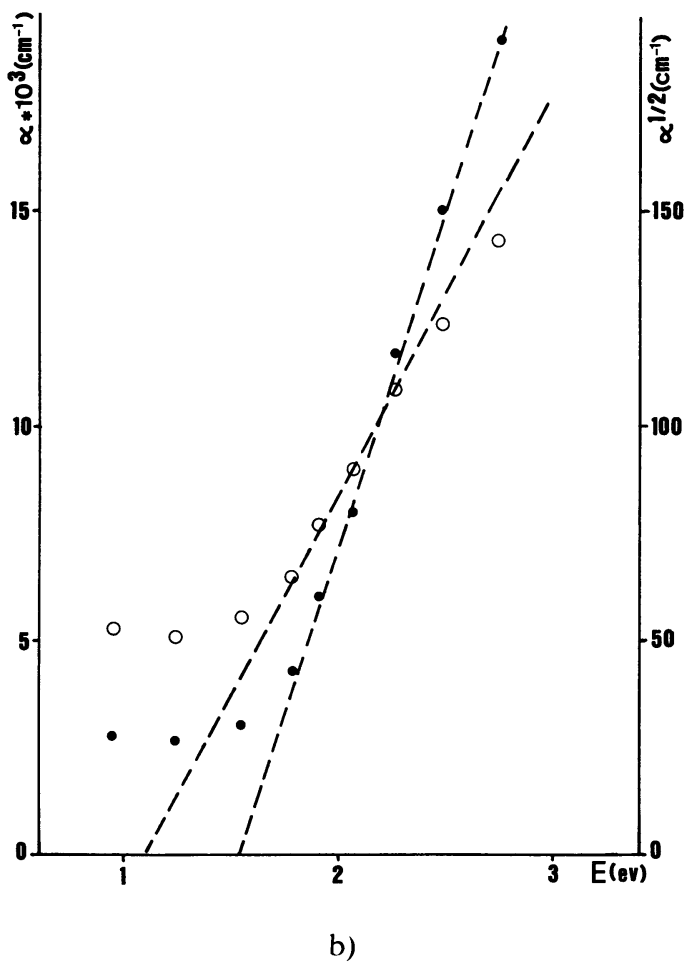

Fig. 7. - Variation in the optical absorption with photon

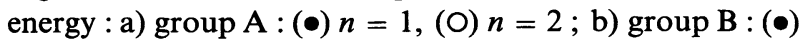
$n=1$, (O) $n=2$. 


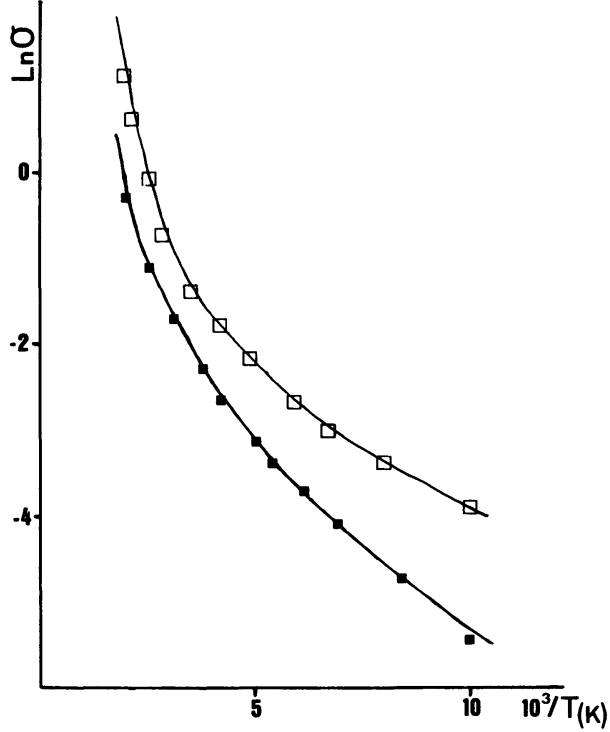

Fig. 8. - Temperature dependence of the electrical resistivity of $\mathrm{MoSe}_{2}$ thin films : ( $\square$ ) group A, ( $\square$ ) group B.

\section{Discussion.}

$\mathrm{MoSe}_{2}$ thin films were synthesized by solid state reaction. ESCA measurements (Tab. I) were found to be in good agreement with those of a powder reference. The measurements of optical gap, $X$ ray diffraction and electron spectroscopy indicates that the films crystallize in the hexagonal system of $\mathrm{MoSe}_{2}$ and they present structural properties similar to those of single crystals. However, while ESCA measurements show us that Mo and Se are bounded in the $\mathrm{MoSe}_{2}$ phase after annealing, $\mathrm{X}$ ray diffraction measurements show us that in situ annealed films are badly crystallized.

The scanning electron micrographs show that annealing under selenium pressure (group B samples) introduces a change in films morphology. While in situ annealed films (group A samples) are very smooth, a granular microstructure appears at the surface of the samples of the group B (Figs. 4 and 5).

All these results show that, while thin stoichiometric $\mathrm{MoSe}_{2}$ films may be synthesized, they are badly crystallized when annealed in situ under vacuum, even at temperature as high as $850 \mathrm{~K}$.

However, the ambiant temperature conductivity of the films decreases by two or three decades compared to $\mathrm{MoSe}_{2}$ DC sputtered films [6], even when the films are submitted to an identical post annealing process $\left(\sigma_{300 \mathrm{~K}}=27 \times 10^{-2} \Omega^{-1} \mathrm{~cm}^{-1}(\mathrm{~A}\right.$ samples), $\quad 15 \times 10^{-2} \Omega^{-1} \mathrm{~cm}^{-1} \quad$ (B samples), $0.1 \times 10^{-2}$ to $0.01 \times 10^{-2} \Omega^{-1} \mathrm{~cm}^{-1}$ DC sputtered films [6] and $2.5 \times 10^{-2} \Omega^{-1} \mathrm{~cm}^{-1}$ for RF sputtered films [9] after annealing post-deposition treatment).

These differences may be explained by higher disorder at the grain boundaries between $\mathrm{MoSe}_{2}$ crystallites in these sputtered films.
The Mo-Se films in the as-sputtered state were always Se deficient. The $\mathrm{MoSe}_{2}$ stoichiometry was obtained with a post-annealing in a Se vapour environment, by Se diffusion from the Se vapour environment to the thin films. Due to the formation of $\mathrm{MoSe}_{2}$, the films might have become less continuous, as shown by electron micrographs [6], which would account for the higher resistivity values observed.

In the case of the evaporated samples of the group B the Mo-Se sandwich films are deposited in a ratio calculated to achieve the desired composition. Therefore, the $\mathrm{MoSe}_{2}$ may be obtained without any apparition of any cracks (Fig. 4).

Moreover the orientation is better in the samples of the group B than in the DC sputtered films. $80 \%$ of the crystallites have their $c$ axis perpendicular to the plane of the substrate in the first case, while only 30 to $60 \%$ in the latter case.

The study of the variation of the conductivity with temperature confirms the influence of grain boundaries. The films being polycrystallines (with small grain size), the effect of the grain boundaries cannot be ignored. Therefore, the grain boundary theories have to be taken into account [14-16].

From the width of the depleted region $W$, created by the grain boundaries, and from $N$ the acceptor atomic concentration $\left(\mathrm{cm}^{-3}\right)$, a certain concentration $N^{*}$ exists for which the grains are only partially depleted ( $2 W<d, d$ being the grain size) if $N>N^{*}$, otherwise the grains are totally depleted (2 $\left.W>d, N<N^{*}\right)$. It has been shown that [16] :

- when $N^{*}>N$,

$$
\sigma \propto T \exp -\left(\frac{E_{g} / 2+e_{\mathrm{T}}}{k T}\right)
$$

- when $N^{*}<N$,

$$
\sigma \propto T^{1 / 2} \exp -\left(\frac{\phi_{\mathrm{B}}}{k T}\right) .
$$

Where $e_{\mathrm{T}}(\mathrm{eV})$ is the trapping state energy referred to $E_{\mathrm{i}}$ at the grain boundary, $\phi_{\mathrm{B}}(\mathrm{eV})$ is the barrier height.

The figure 9 shows that above $300 \mathrm{~K}$ the best fit is obtained by plotting $\ln \sigma T^{1 / 2}$ versus $10^{3} / T$ i.e. when the grains are partially depleted and the barrier height may be estimated (Tab. III).

As shown table III the averaged barrier height in DC sputtered films is higher than that of group A and B samples, which is in agreement with the hypothesis of higher disorder at the grain boundaries between $\mathrm{MoSe}_{2}$ microcrystallites in DC sputtered films. Below $300 \mathrm{~K}$ (Fig. 9) a good fit with the grain boundary law cannot be obtained. Others phenomenum have to be taken into account.

The low activation energies on the low temperature range $(T<200 \mathrm{~K})$, may induce a hopping 


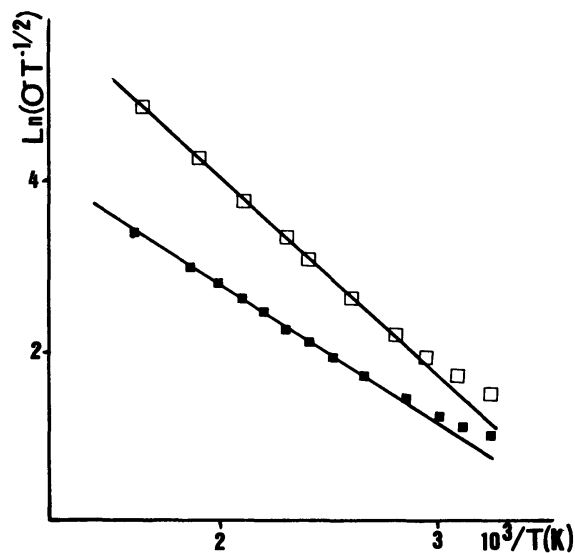

a)

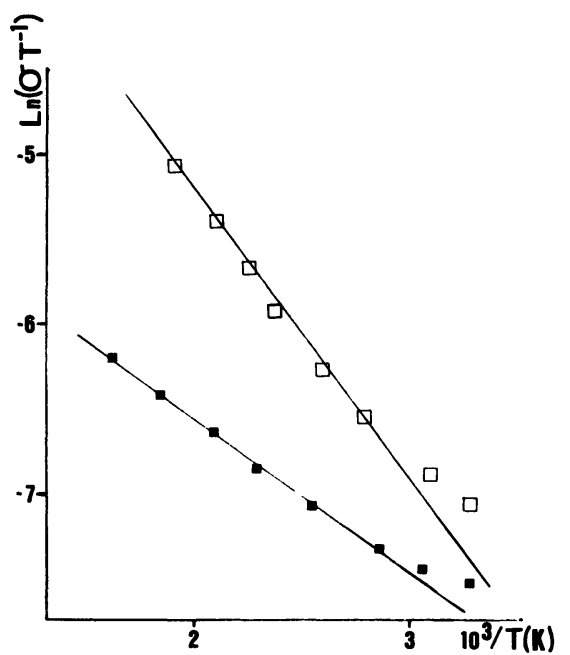

b)

Fig. 9. - Grain boundaries scattering mechanisms for typical layers of the group A ( $\square$ ) and the group B ( $\square$ ). a) $\operatorname{Ln} \sigma T^{1 / 2}$ vs. $10^{3} / T$, b) $\operatorname{Ln} \sigma T^{-1}$ vs. $10^{3} / T$.

conduction [17-19]. The existence of the localized states necessary for such a conduction process is a consequence of imperfections associated with polycrystalline films [17].

Mott [20] and Efros [21] propose two different mechanisms of hopping conduction between localized states, the variable-range hopping conduction and hopping conductivity tied to a Coulomb gap respectively.

The Mott law gives:

$$
\sigma T^{1 / 2} \simeq \exp -\left(\frac{T_{\mathrm{M}}}{T}\right)^{1 / 4}
$$

and Efros law gives:

$$
\sigma T \simeq \exp -\left(\frac{T_{\mathrm{E}}}{T}\right)^{1 / 2} .
$$

Plots of $\operatorname{Ln}\left(\sigma T^{1 / 2}\right)$ versus $T^{-1 / 4}$ and $\operatorname{Ln} \sigma T$ versus $T^{-1 / 2}$ are shown in figure 10 . While the Mott law

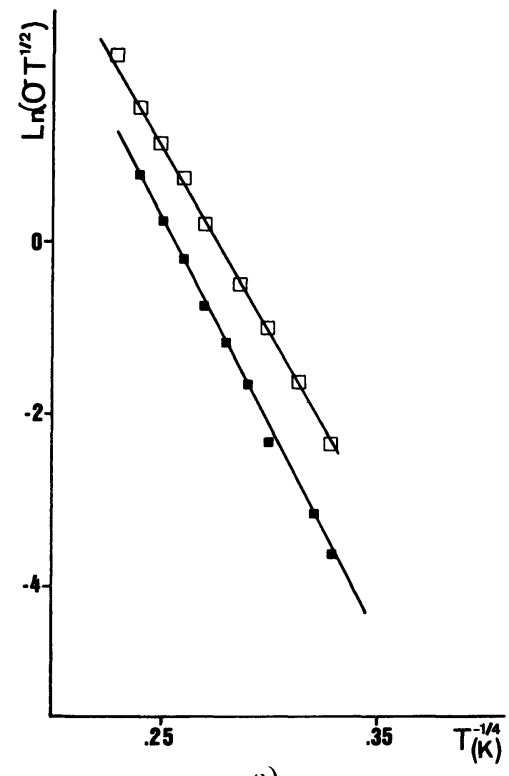

a)

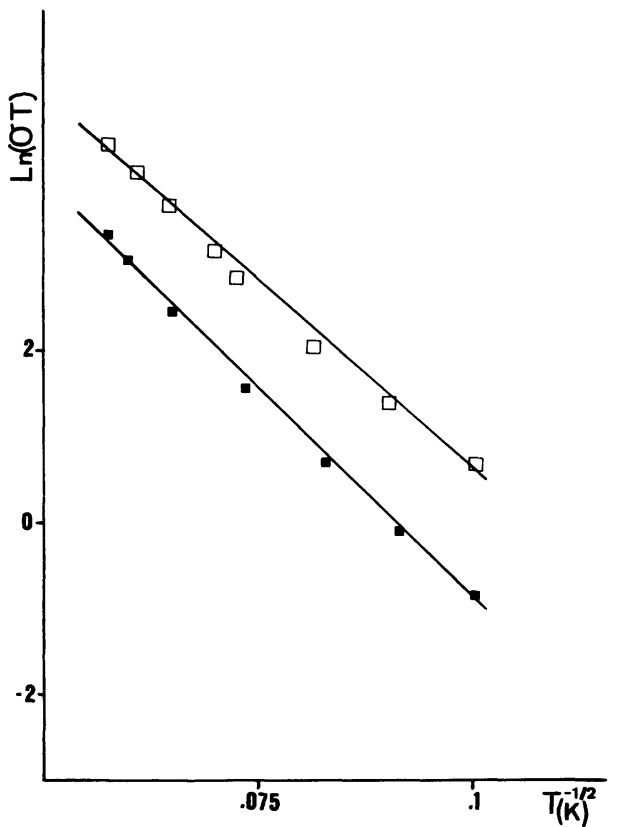

b)

Fig. 10. - Hopping conduction in the temperature range 80 to $200 \mathrm{~K}$ for typical layers of the group $\mathrm{A} \mathrm{( \square )}$ and the group B (口). a) $\operatorname{Ln} \sigma T^{1 / 2} v s . T^{-1 / 4}$, b) $\operatorname{Ln} \sigma T$ vs. $T^{-1 / 2}$.

gives a good fit (Fig. 9a) the Efros law (Fig. 9b) cannot be excluded. More, Pistoulet and coworkers [22] have shown that, often, conductivity phenomenum attributed to hopping conductivity may be fitted by a long range potential fluctuations model. In order to discriminate between these hypothesis, ac conductivity measurements should be realized [22].

Today we can only say that the grain boundary model alone cannot explain the variation of the conductivity with the temperature in all the temperature range investigated. 


\section{Conclusion.}

A new technique to obtain $\mathrm{MoSe}_{2}$ thin films has been described. Compared to preceeding DC sputtered thin films [6] the orientation of the microcrystallites is better in the samples of the group B, $80 \%$ of the crystallites have their $c$ axis perpendicular to the plane of the substrate while only 30 to $60 \%$ in the DC sputtered films have this orientation. The ambiant temperature conductivity of the films decreases by two or three decades compared to $\mathrm{MoSe}_{2}$ DC sputtered films [6], even when the films are submitted to an identical post annealing process.
All these results are encouraging for application to the electrochemical photocells if we manage to obtain an optimization of the crystallisation of the in situ annealed films which are the less polluted (Fig. 2c). So we study a device permitting in situ annealing under selenium pressure.

\section{Acknowledgments.}

The authors wish to thank Mrs Bohn, Barreau, Péhé for measurements performed.

\section{References}

[1] Goldberg A. M., Beal A. R., Lévy F. A. and DAvis E. A., Philos. Mag. 32 (1975) 367.

[2] Tributsch H., Solar Energy Mater 1 (1979) 257.

[3] Tributsch H., SAKA J. and KaWAï T., Electrochem. Acta 26 (1981) 21.

[4] Kline G., KaM K. K., Ziegler Q. and Parkinson B. A., Solar Energy Mater 6 (1982) 337.

[5] Chandra S., Pandey R. K., Phys. Status Solidi (a) 72 (1982) 415

[6] Mallouky A. and Bernède J. C., Thin Solid Films 158 (1988) 285.

[7] Bernède J. C., Mallouky A., Pouzet J., Mater. Chem. Phys. 20 (1988) 201.

[8] Bichsel R. and Lévy F., Thin Solid Films 116 (1984) 367.

[9] BiCHSEL R. and LÉvY F., Thin Solid Films 124 (1985) 75.

[10] Bichsel R. and LÉvy F., Thin Solid Films 131 (1985) 87.

[11] Dang Tran Quan, Thin Solid Films 149 (1987) 197.

[12] Mallouky A., Thésis (3ème cycle) Nantes (1987).

[13] Wagner C. D., Riggs W. M., Davis L. E., Moulder J. F. and MuILENberg G. E., Handbook of X-ray Photoelectron Spectroscopy (Perkin Elmer. Corp., Physical. Electronics Div., Eden Prairie, Min., USA) 1979.

[14] Seto S. Y., J. Appl. Phys. 46 (1975) 5247.

[15] Baccarani G., Rico B. and Spadini G., J. Appl. Phys. 49 (1978) 5565.
[16] Lu C. C., Luan C. Y., Meindl J. O., I.E.E.E. Trans. Electron Devices 28 (1981) 818.

[17] Phahle A. M., Thin Solid Films 41 (1977) 235.

[18] Dawar A. L., ANil Kumar, Mall R. P. and MAthur P. C., Thin Solid Films 112 (1984) 107.

[19] SRIDEVI D. and RedDY K. V., Thin Solid Films 141 (1986) 157.

[20] MotT N. F., Philos. Mag. 19 (1969) 835 ;

MotT N. F. and DAvis E. J. A., Electronic Processes in Non-Crystalline Materials, $2^{\text {nd }}$ Edition (Clarendon Press, Oxford) 1979.

[21] Efros A. L. and ShklovskiJ B. I., J. Phys. (1975) 149 ;

Efros A. L., Nguyen V. L. and ShklovskiJ B. I., Solid State Commun. 82 (1979) 851 ;

Efros A. L. and SchKlovskiJ B. I., ElectronElectron Interaction in Disordered Systems, Eds. A. L. Efros and M. Pollak (Elsevier Science Publishers B.V.) 1985 ;

ShklovskiJ B. I. and Efros A. L., Springer Ser. Solid States 45 (1984).

[22] Roche F. M., Pistoulet B. and Soegandi T., $J$. Phys. France 49 (1988) 1933 ;

Pistoulet B. and Hamamdjian G., Phys. Rev. B 35 (1987) 6305 ;

Pistoulet B., Roche F. M. and Abdalla S., Phys. Rev. B 30 (1984) 5987.

[23] JANda M. and Kubovy A., Phys. Status Solidi A 35 (1976) 397. 